\title{
SERBUK KACA SEBAGAI BAHAN TAMBAH PEMBUATAN BETON NORMAL BERDASARKAN GRADASI PASIR ZONA 3
}

\author{
Sumanti Sri Sejati'), Luky Indra Gunawan ${ }^{2)}$ \\ 1) Fakultas Teknik, Program Studi Teknik Sipil, Universitas Veteran Bangun Nusantara, Sukoharjo, J1. \\ Letjen Sudjono Humardhani, No.1, Jombor, Sukoharjo; Telp. 0271-593156. \\ Email: sumantisrisejati@gmail.com \\ 2) Fakultas Teknik, Program Studi Teknik Sipil, Universitas Veteran Bangun Nusantara, Sukoharjo, J1. \\ Letjen Sudjono Humardhani, No.1, Jombor, Sukoharjo; Telp. 0271-593156. \\ Email: lukyindra35@gmail.com
}

\begin{abstract}
Abstrak
Beton merupakan bahan utama pada struktur bangunan. Beton dibuat dengan mencampur antara semen, pasir, kerikil, air, dan bahan tambah yang bervariasi dengan perbandingan tertentu. Seiring perkembangan jaman inovasi beton dengan bahan tambah mengalami penyempurnaan. Pada penelitian ini mengetahui komposisi optimum penambahan serbuk kaca berdasarkan gradasi pasir zona 3 terhadap kuat tekan beton, dengan penambahan sebuk kaca sebesar 15\%, 20\%, 25\%, dan 30\% menggunakan benda uji silinder diameter $15 \mathrm{~cm}$ dan tinggi $30 \mathrm{~cm}$ sebanyak 15 buah sempel benda uji. Penguian dilakuakan pada umur 28 hari untuk mengetahui kuat tekan pada umur maksimal. Dari hasil uji kuat tekan beton serbuk kaca mengalami peningkatan pada variasi $15 \%$ dan 30\% sebesar $27 \mathrm{MPa}$ dan 24,99 $\mathrm{MPa}$ dibandingkan beton normal 22,54 MPa. Maka kesimpulannya penambahan serbukaca dapat meningkatkan kuat tekan beton.
\end{abstract}

Kata kunci: Serbuk kaca, Beton normal, Pasir zona 3

\begin{abstract}
Concrete is the main ingredient in building structures. Concrete is made by mixing cement, sand, gravel, water, and added ingredients which vary with certain comparisons. Along with the development of the era of concrete innovation with added ingredients experienced improvements. In this study knowing the optimum composition of glass powder addition based on zone 3 sand gradation on compressive strength of concrete, with the addition of a glass of 15\%,20\%, 25\%, and 30\% using cylindrical specimens $15 \mathrm{~cm}$ in diameter and $30 \mathrm{~cm}$ high by 15 pieces sample the test object. Penguian is done at the age of 28 days to determine the compressive strength at the maximum age. From the results of the test results, the compressive strength of glass powder concrete has increased in variations of $15 \%$ and $30 \%$ by $27 \mathrm{MPa}$ and $24.99 \mathrm{MPa}$ compared to normal concrete at $22.54 \mathrm{MPa}$. So the conclusion is the addition of powder can increase the concrete compressive strength.
\end{abstract}

Keywords: Glass powder, normal concrete, sand zone 3

\section{PENDAHULUAN}

\section{Latar Belakang}

Beton (concrete) adalah material yang paling sering digunakan diseluruh dunia selain baja (steel). Beton banyak digunakan untuk memenuhi kebutuhan dalam proyek pembangunan insfastruktur seperti jalan, gedung, bendungan, jembatan, dan sebagainya. Beton diperoleh dari pencampuran semen, agregat halus (fine aggregate), agregat kasar (coase aggegate) dan air. Dengan menambahkan bahan perekat (semen) dengan takaran tertentu, dan air sebagai bahan pembantu untuk keperluan reaksi kimia selama proses pengerasan dan perawatan beton (concrete curing). Nilai kekuatan dan daya tahan (durability) beton merupakan fungsi dari sekian banyak faktor, beberapa diantaranya nilai banding campuran dan mutu bahan susun, metode pelaksanaan pengecoran, temperatur, pelakasanaan akhir (finishing), dan perawatan (curing) beton.

Beton mutu normal adalah beton yang mengandung agregat normal yang diperoleh dari agregat alam yang dipecah atau tanpa dipecah sehingga diperoleh berat jenis diudara atau berat massa volume beton antara 2100 $2550 \mathrm{~kg} / \mathrm{m} 3$ menuut ACI. Kuat tekan beton mutu normal 20 - 35 Mpa pada umur 28 hari. Beton mutu normal biasanya dipakai untuk konstruksi-konstruksi sederhana seperti perumahan dan bangunan - bangunan gedung yang relatif tidak terlalu tinggi., dimana kuat tekan yang dibutuhkan tidak terlalu besar. Proses pelaksanaan pekerjaan konstruksi 
dengan mengunakan beton mutu normal tidak terlalu menuntut tingkat ketelitian dan keamanan yang tinggi, dan bahan - bahan dasar pembentuknya mudah diperoleh serta ekonomis.

Kelemahan beton mutu normal yaitu mempunyai kekuatan yang kecil serta sifat sifat khusus yang terbatas. Sifat khusus yang dimaksud antara lain kedap air, lebih tahan terhadap agresi kimiawi, tahan terhadap pengaruh lingkungan dimana beton tesebut digunakan, dan lain sebagainya (Murdock L.J, Brook K.M, 1986).

Tabel 1. Mutu beton

\begin{tabular}{|c|c|l|}
\hline $\begin{array}{c}\text { Jenis } \\
\text { beton }\end{array}$ & $\begin{array}{c}\text { Mutu beton } \\
\text { (MPa) }\end{array}$ & \multicolumn{1}{|c|}{ Uraian } \\
\hline $\begin{array}{c}\text { Mutu } \\
\text { tinggi }\end{array}$ & $35-65$ & $\begin{array}{l}\text { Umumnya digunakan } \\
\text { untuk beton prategamg } \\
\text { seperti tiang pancang } \\
\text { beton prategang, gelagar } \\
\text { beton prategang, pelat } \\
\text { beton prategang dan } \\
\text { sejenisnya. }\end{array}$ \\
\hline $\begin{array}{c}\text { Mutu } \\
\text { sedang }\end{array}$ & $20-35$ & $\begin{array}{l}\text { Umumnya digunakan } \\
\text { untuk beton bertulang, } \\
\text { diafragma, kerb beton } \\
\text { pracetak, beton } \\
\text { bertulang, bangunan. }\end{array}$ \\
\hline $\begin{array}{c}\text { Mutu } \\
\text { rendah }\end{array}$ & $15-20$ & $\begin{array}{l}\text { Umumnya digunakan } \\
\text { untuk struktur beton } \\
\text { tanpa tulangan seperti } \\
\text { beton siklop, trotoar dan } \\
\text { pasang batu kosong yang } \\
\text { diisi adukan. }\end{array}$ \\
\hline & $10-15$ & $\begin{array}{l}\text { Digunakan sebagai lantai } \\
\text { kerja, penimbunan } \\
\text { kembali dengan beton. }\end{array}$ \\
\cline { 2 - 4 } & & \\
\hline
\end{tabular}

(sumber: puslitbang Prasarana Transportasi,

Divisi 7-2005)

Kaca merupakan materi bening dan trsansparan (tembus pandang) yang biasanya di hasilkan dari campuran silikon atau bahan silikon dioksida ( $\mathrm{SiO} 2)$, yang secara kimia sama dengan kuarsa (bahasa inggris : kwarts). Suhu lelehnya adalah 2000 Derajat Celcius. Jenis kaca yang paling umum dikenal dan yang telah digunakan sejak berabad - abad silam sebagai jendela dan gelas minum adalah kaca soda kapur, yang terbuat dari $75 \%$ silica ( $\mathrm{SiO} 2)$ ditambah $\mathrm{Na} 2 \mathrm{O}$, Cao, dan sedikit aditif lain.

Dari segi kimia, kaca adalah gabungan dari berbagai oksida anorganik yang tidak mudah menguap, yang dihasilkan dari dekomposisi dan peleburan senyawan alkali dan alkali tanah, pasir serta berbagai golongan kramik lainnya. Kekhasan sifat - sifat kaca ini terutama dipengaruhi oleh keunikan silika (SiO2) dan proses pembentuknnya (Pradana,2013).

Limbah kaca merupakan limbah yang banyak dihasilkan dari kehidupan masyarakat terutama dikota besar. Limbah kaca setiap hari semakin meningkat volumenya karena banyak kegiatan manusia yang menghasilkan kaca, sebagian besar limbah kaca langsung dibuang kelahan terbuka, hal ini tentu saja akan mencemari lingkungan mengingat kaca merupakan material yang tidak dapat didaur ulang secara alami oleh alam.

Oleh karena itu harus dilakukan inovasi untuk mengurangi limbah kaca, salah satunya dengan memanfaatkan limbah kaca yang ada sebagai salah satu material campuran beton (Ayu Suhartini,dkk, 2014).

Limbah kaca memiliki potensi dan dipandang strategis sebagai bahan penyusun silika ( $\mathrm{SiO} 2)$ diatas $60 \%$ memiliki sifat unggul berupa titik lebur yang tinggi $\left(1400^{\circ} \mathrm{C}-1600^{\circ} \mathrm{C}\right)$ dan sifat mekanik yang sangat kuat.

Pasir zona 3 merupakan jenis pasir sedang yang memiliki gradasi agak halus (tidak terlalu lembut dan kasar) dengan presentase lolosan ayakan antara 1,5 sampai 3,8 dan terdiri dari butiran-butiran beraneka ragam.

Gunawan(2019), tentang Efektifitas penggunaan serbuk kaca sebagai pengganti sebagian pasir pada pembuatan beton mengatakan penambahan variasi serbuk kaca terhadap berat pasir meningkatkan kuat tekan beton. Pada penelitian ini bubuk kaca digunakan sebagai substitusi sebagian pasir dengan kadar 5\%, 10\%, 15\%, dan $20 \%$. Peningkatan terjadi pada kadar variasi $15 \%$ serbuk kaca kasar sebesar 22,8 MPa dan 30\% serbuk kaca campuran sebesar 21,12 MPa.

Dalam penelitian ini menggunakan serbuk kaca sebagai bahan tambah dalam pembuatan beton normal guna mencapai kuat tekan optimal.

Batasan masalah penelitian ini beton di uji pada umur 28 hari dengan kuat tekan rencana beton normal sebesar $20 \mathrm{Mpa}$, presentase penambahan serbuk kaca sebesar 15\%, 20\%, $25 \%$ dan $30 \%$ dari berat pasir yang di hitung berdasarkan gradasi pasir zona 3 . 


\section{METODE}

\section{Bahan dan Alat}

Bahan yang di guanakan pada penelitian ini adalah semen, pasir, kerikil, air, dan serbuk kaca. Untuk alat yang digunakan yaitu concrete compression machine, neraca digital, gelas ukur, ayakan satu set, cetakan silinder diameter $15 \mathrm{~cm}$ dan tinggi $30 \mathrm{~cm}$, mixer.

\section{Metode penelitian}

Dalam penelitian ini pasir dan kerikil diuji dahulu sebelum digunakan untuk campuran beton. Pengujian pasir dan kerikil meliputi pengujian gradasi, kadar lumpur, penyerapan air, berat jenis, dan kadar air. Untuk pembuatan rencana campuran beton menggunakan perancangan beton menurut SNI 03-2834-2000. Menggunakan benda uji berbentuk silinder dengan ukuran dengan ukuran diameter $15 \mathrm{~cm}$, dan tinggi $30 \mathrm{~cm}$.

Selanjutnya kode BN digunakan pada beton normal. Kode BSK digunakan pada beton bahan tambah serbuk kaca.

\section{HASIL DAN PEMBAHASAN}

\section{Hasil Uji Slump}

Tabel 2. Hasil uji slump

\begin{tabular}{llc}
\hline No & Kadar variasi & $\begin{array}{c}\text { Hasil Uji Slump } \\
(\mathrm{cm})\end{array}$ \\
\hline 1 & BN & $1,5 \mathrm{~cm}$ \\
\hline 2 & BSK 15\% & $1,5 \mathrm{~cm}$ \\
\hline 3 & BSK 20\% & $1,5 \mathrm{~cm}$ \\
\hline 4 & BSK 25\% & $1,5 \mathrm{~cm}$ \\
\hline 5 & BSK 30\% & $1,5 \mathrm{~cm}$ \\
\hline
\end{tabular}

Hasil pengujian slump beton nomal hasil pengujian $1,5 \mathrm{~cm}$, beton dengan variasi $15 \%$ dengan hasil $1,5 \mathrm{~cm}$, beton dengan variasi $20 \%$ dengan hasil $1,5 \mathrm{~cm}$, beton dengan variasi $25 \%$ dengan hasil $1,5 \mathrm{~cm}$, beton dengan variasi $30 \%$ dengan hasil $1,5 \mathrm{~cm}$. Dengan demikian beton dengan bahan tambah sebuk kaca tidak mempengaruhi slump dengan hasi $1,5 \mathrm{~cm}$ sama dengan slump beton normal sebesar $1,5 \mathrm{~cm}$.

\section{Hasil Uji Kuat Tekan}

Tabel 3. Hasil Uji kuat tekan

\begin{tabular}{|c|c|c|c|c|c|c|}
\hline No & $\begin{array}{c}\text { Kadar } \\
\text { Penambahan } \\
\text { serbuk kaca }\end{array}$ & $\begin{array}{c}\text { Berat } \\
\text { beton } \\
\text { silinder } \\
\text { (Kg) }\end{array}$ & $\begin{array}{c}\text { Kode Benda } \\
\text { Uji }\end{array}$ & $\begin{array}{l}\text { Umur } \\
\text { Beton }\end{array}$ & $\begin{array}{c}\text { Kuat Tekan } \\
\text { (MPa) }\end{array}$ & $\begin{array}{c}\text { Kuat Tekan } \\
\text { Rata-Rata } \\
\text { (MPa) }\end{array}$ \\
\hline \multirow[t]{5}{*}{1} & $0 \%$ & 13,2 & BN. $0 \%$ & 28 & 24,91 & 22,54 \\
\hline & & 13 & BN. 0\% & 28 & 21,63 & \\
\hline & & 13,5 & BN. 0\% & 28 & 19,76 & \\
\hline & & 13,3 & BN. 0\% & 28 & 21,40 & \\
\hline & & 13,3 & BN. 0\% & 28 & 24,98 & \\
\hline \multirow[t]{3}{*}{2} & $15 \%$ & 13,5 & BSK. $15 \%$ & 28 & 28,54 & 27,00 \\
\hline & & 13,4 & BSK. $15 \%$ & 28 & 35,61 & \\
\hline & & 13,3 & BSK. $15 \%$ & 28 & 16,87 & \\
\hline \multirow[t]{3}{*}{3} & $20 \%$ & 13,5 & BSK. $20 \%$ & 28 & 19,14 & 22,00 \\
\hline & & 13,1 & BSK. $20 \%$ & 28 & 25,25 & \\
\hline & & 13,1 & BSK. 20\% & 28 & 21,63 & \\
\hline \multirow[t]{3}{*}{4} & $25 \%$ & 13,2 & BSK. $25 \%$ & 28 & 16,30 & 17,93 \\
\hline & & 13,2 & BSK. $25 \%$ & 28 & 20,61 & \\
\hline & & 12,9 & BSK. 25\% & 28 & 16,19 & \\
\hline \multirow[t]{3}{*}{5} & $30 \%$ & 13,0 & BSK. $30 \%$ & 28 & 24,29 & 24,99 \\
\hline & & 12,8 & BSK. $30 \%$ & 28 & 22,99 & \\
\hline & & 12,8 & BSK. $30 \%$ & 28 & 27,69 & \\
\hline
\end{tabular}




\section{Grafik Kuat Tekan}

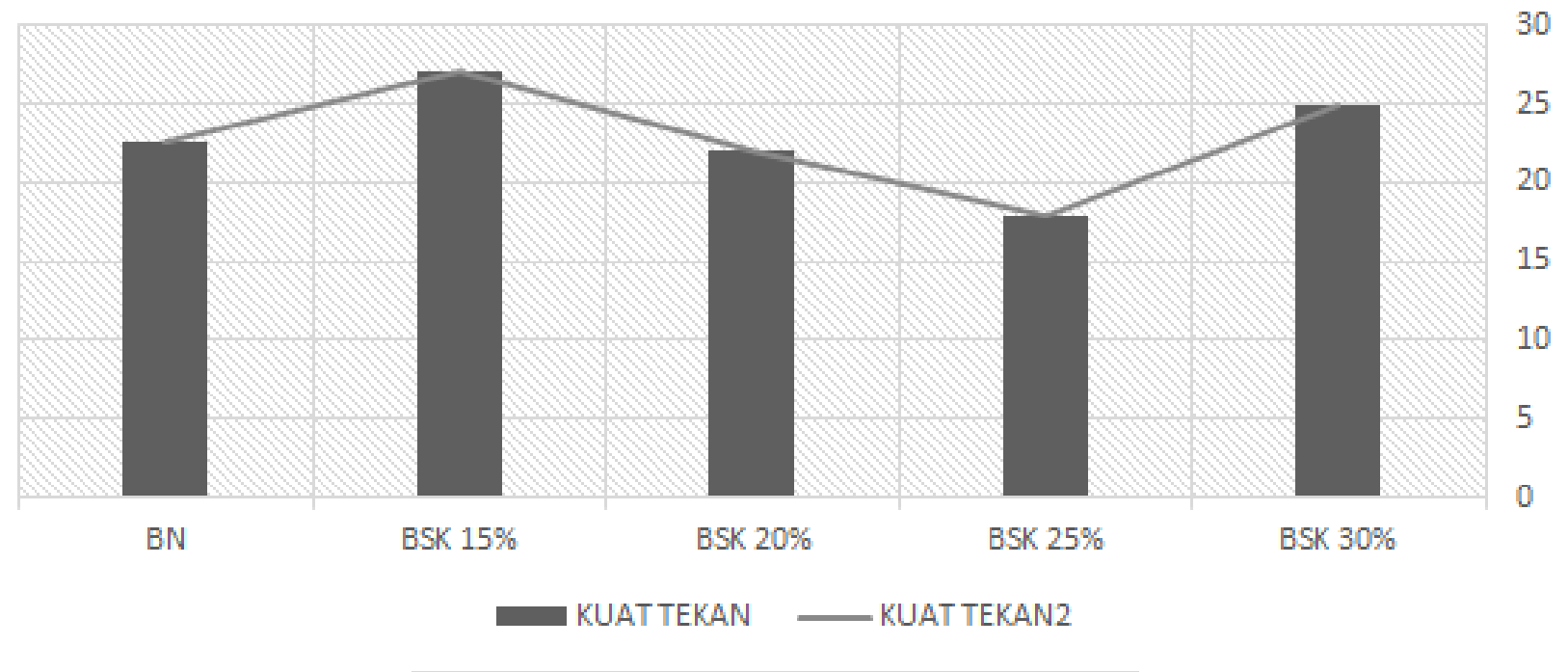

Gambar 1. Grafik kuat tekan

Dari Tabel 3 kuat tekan beton normal sebesar 24,91 $\mathrm{MPa}, 21,63 \mathrm{MPa}, 19,76 \mathrm{MPa}, 21,40$ $\mathrm{MPa}$, dan 24,98 MPa dengan rata - rata sebesar 22,54 MPa. Kuat tekan beton dengan bahan tambah serbuk kaca $15 \%$ sebesar 28,54 MPa, $35,61 \mathrm{MPa}$, dan $16,87 \mathrm{MPa}$ dengan rata - rata sebesar 27,00 MPa. Kuat tekan beton dengan bahan tambah serbuk kaca 20\% sebesar 19,14 $\mathrm{MPa}, 25,25 \mathrm{MPa}$, dan 21,63 MPa dengan rata rata sebesar 22,00 $\mathrm{MPa}$. Kuat tekan beton dengan bahan tambah serbuk kaca $25 \%$ sebesar 16,30 MPa, 16,87 MPa, dan 20,61 MPa dengan rata - rata sebesar 17,93 Mpa. Kuat tekan beton dengan bahan tambah serbuk kaca $30 \%$ sebesar 24,29 MPa, 22,99 MPa, dan 27,69 $\mathrm{MPa}$ dengan rata - rata sebesar 24,99 $\mathrm{MPa}$.

Dari gambar 1 kuat tekan beton dengan bahan tambah serbuk kaca 15\% dan 30\% mengalami peningkatan sebesar 27,00 $\mathrm{MPa}(19,8 \%)$ dan $24,99 \mathrm{MPa}(10,9 \%)$ dari kuat tekan beton normal sebesar 22,54 MPa. Kuat tekan beton dengan bahan tambah serbuk kaca 20\% dan $25 \%$ mengalami penurunan sebesar 22,00 $\mathrm{MPa}$ $(2,4 \%)$ dan $17,93 \mathrm{MPa}(20,4 \%)$ dari kuat tekan beton normal sebesar 22,54 MPa.

\section{SIMPULAN}

Penambahan serbukaca dapat meningkatkan kuat tekan beton beton dengan bahan tambah serbuk kaca $15 \%$ dan $30 \%$ mengalami peningkatan sebesar 27,00 $\mathrm{MPa}(19,8 \%)$ dan $24,99 \mathrm{MPa}(10,9 \%)$ dari kuat tekan beton normal sebesar 22,54 MPa. dengan bahan tambah serbuk kaca $20 \%$ dan $25 \%$ mengalami penurunan kuat tekan sebesar 22,00 $\mathrm{MPa}$ $(2,4 \%)$ dan $17,93 \mathrm{MPa}(20,4 \%)$ dari kuat tekan beton normal sebesar 22,54 MPa.

\section{DAFTAR PUSTAKA}

Ayu Suhartini. Anita Setyowati Srie Gunarti. Azharie Hasan. 2014. Pengaruh Penambahan Tumbukan Limbah Botol Kaca Sebagai Bahan Subtitusi Agregat Halus Terhadap Kuat Tekan dan Kuat Lentur

Luky Indra Gunawan. 2019. Efektivitas Penggunaan Serbuk Kaca Sebagai Pengganti Sebagian Pasir Pada Pembuatan Beton

Murdock L. J. Brook. K. M.1986. Bahan Dan Praktek Beton. Terjemahan 1r. Stephanus Hindarko. Erlangga. Jakarta.

Pradana, 2013, Makalah Pengertian dan Aplikasi Kaca

Puslitbang Prasarana Transportasi, Divisi 7 2005 